\title{
РАЗМЕЩЕНИЕ ОБЪЕКТОВ СПГ НА СЕТИ ЖЕЛЕЗНЫХ ДОРОГ КАЗАХСТАНА ПРИ ЭКСПЛУАТАЦИИ ТЕПЛОВОЗОВ НА ГАЗОМОТОРНОМ ТОПЛИВЕ
}

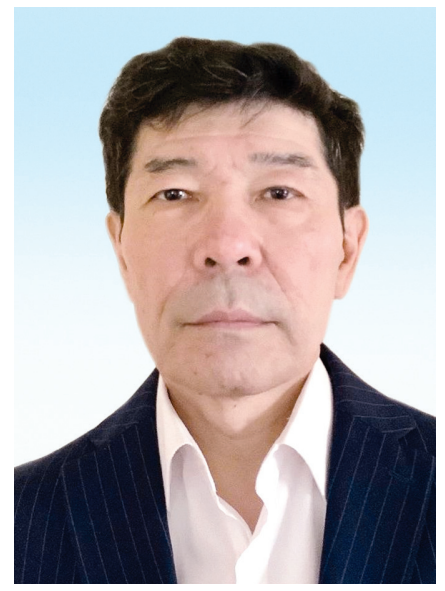

Б.Б. ЖАРДЕМОВ ${ }^{1}$, доктор технических наук, генеральный директор, https://orcid.org/0000-00027021-4675

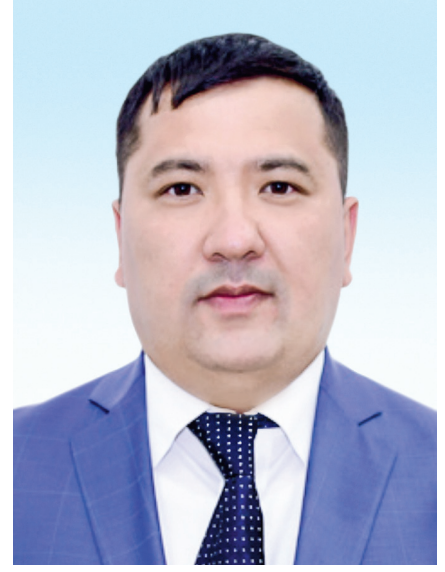

T.A. КАНАТБАEB ${ }^{2}$, кандидат технических наук, директор департамента технического регулирования и развития,

https://orcid.org/0000-00025229-2768

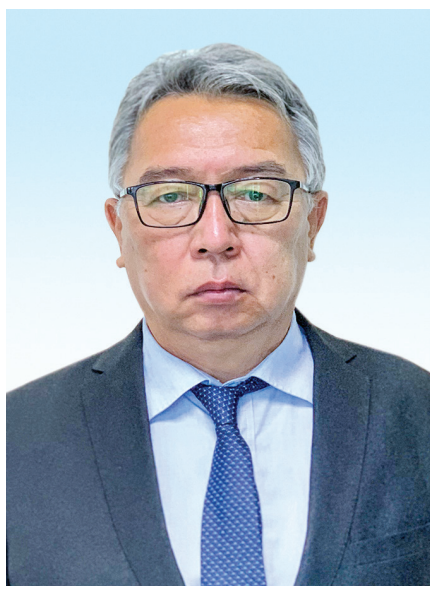

T.C. АРЫСТАНБАЕВ ${ }^{3,1 *}$, директор департамента корпоративного развития и управления активами, и.о. председателя правления

ОЮЛ «Газомоторная ассоциация Казахстана», https://orcid.org/0000-00024926-5208

${ }^{1}$ ТОО «НАУЧНО-ИССЛЕДОВАТЕЛЬСКИЙ ЦЕНТР КОМПЛЕКСНЫХ ТРАНСПОРТНЫХ ПРОБЛЕМ»

Республика Казахстан, 010000, г. Нур-Султан, ул. Г. Мусрепова, 8

${ }^{2}$ АО «НАЦИОНАЛЬНАЯ КОМПАНИЯ «ҚАЗАҚСТАН ТЕМІР ЖОЛЫ» Республика Казахстан, 010000, г. Нур-Султан, ул. Д. Кунаева, 6

ЗТОО «КАЗТРАНСГАЗ ӨНІМДЕРІ»

Республика Казахстан, 010000, г. Нур-Султан, ул. А. Бокейхана, 12

Обоснованы места дислокации основных инфрраструктурных объектов производства, заправки и пунктов экипировки сжиженного природного газа (СПГ) на сети тепловозной тяги железных дорог Казахстана для обеспечения парка тепловозов на газомоторном топливе. Рассмотрены структурные уровни сети железных дорог на тепловозной тяге, определены региональные зоны тепловозной тяги. Предложена методика определения места размещения основных инфраструктурных объектов СПГ с учетом величины перевозимого грузопотока, протяженности плеч обслуживания и зональности. При

\footnotetext{
* Адрес для переписки. E-mail: t.arystanbayev@ktgo.kz
} 
определении мест размещения инфраструктурных объектов СПГ принято также во внимание расположение газопроводной сети природного газа на территории Казахстана.

КЛЮЧЕВЫЕ СЛОВА: СПГ (сжиженный природный газ), газомоторное топливо, тепловоз на газомоторном топливе, СПГ инфраструктура, пункты экипировки тепловоза, сеть тепловозной тяги.

\section{ГАЗ МОТОРЛАРЫ ОТЫНЫМЕН ТЕПЛОВОЗДАРДЫ ПАЙДАЛАНУ КЕЗІНДЕ ҚАЗАҚСТАН ТЕМІР ЖОЛДАРЫ ЖЕЛІСІНДЕ СТГ ОБЪЕКТІЛЕРІН ОРНАЛАСТЫРУ}

Б.Б. ЖАРДЕМОВ1', техника ғылымдарының докторы, бас директоры, https://orcid.org/0000-00027021-4675;

Т.А. ҚАНАТБАЕВ ${ }^{2}$, техника ғылымдарының кандидаты, техникалық реттеу және дамыту департаментінің директоры, https://orcid.org/0000-0002-5229-2768;

T.C. AРЫСТАНБАЕВ ${ }^{3,1 *}$, корпоративтік даму және активтерді басқару департаментінің директоры, «Қазақстанның газ моторлы Қауымдастығы» ЗТБ Басқарма төрағасының мезгілді орындаушы, https://orcid.org/0000-0002-4926-5208

${ }^{1}$ «КЕШЕНДІ КӨЛІК МӘСЕЛЕРІН ҒЫЛЫМИ-ЗЕРТТЕУ ОРТАЛЫҒЫ» ЖШС, Қазақстан Республикасы, 010000, Нұр-Сұлтан қ., Ғ. Мүсірепов көшесі, 8

${ }^{2}$ «KAZAKHSTAN RAILWAYS», JSC,

6, D. Kunayev street, Nur-Sultan, 010000, Kazakhstan

З«ҚАЗТРАНСГАЗ ӨНІМДЕРІ» ЖШС

Қазақстан Республикасы, 010000, Нұр-Сұлтан қаласы, Ә. Бөкейхан көшесі, 12

Мақалада газ моторлы отынмен тепловоздар паркін қамтамасыз ету үшін Қазақстан темір жолдарының тепловозды тарту желісінде сұйытылған табиғи газды (СТГ) өндірудің, құюдың негізгі инфррақұрылымдық объектілерін және жабдықтау пункттерін орналастыру орнын негіздеу жүзеге асырылды. Тепловоз тартымындағы темір жол желісінің құрылымдық деңгейлері қарастырылып, аймақтық тартылыс аймақтары анықталды. Тасымалданатын жүк ағынының көлемін, қызмет көрсету иіндерінің ұзындығын және аймақтылығын ескере отырып, СТГ-ның негізгі инфрақұрылымдық объектілерін орналастыру орнын анықтау әдістемесі ұсынылды. СТГ инфрақұрылымдық объектілерін орналастыру орындарын айқындау кезінде Қазақстан аумағында табиғи газдың газ құбыры желісінің орналасуы да назарға алынды.

ТҮЙІн СӨзДЕР: СТГ (сұйытылған табиғи газ), газмоторлы отын, газмоторлы отындағы тепловоз, СТГ Инфрақұрылым, тепловозды жабдықтау пункттері, тепловозды тарту желісі.

\section{PLACEMENT OF LNG FACILITIES ON THE RAILWAYS OF KAZAKHSTAN DURING THE OPERATION OF DIESEL LOCOMOTIVES RUNNING ON GAS-ENGINE FUEL}

B. B. ZHARDEMOV' ${ }^{1}$, General Manager, Doctor of Technical Science, https://orcid.org/0000-0002-70214675;

T.A. KANATBAYEV ${ }^{2}$, D. of Technical Sciences, Manager of the Department of Technical Regulation and Development, https://orcid.org/0000-0002-5229-2768;

T.S. ARYSTANBAYEV ${ }^{3,1}$, Manager of the Corporate Development and Asset Management Department, https://orcid.org/0000-0002-4926-5208

${ }^{1}$ «RESEARCH CENTER OF COMPLEX TRANSPORT PROBLEMS», LLP,

8, G. Musrepov street, Nur-Sultan, 010000, Kazakhstan 
${ }^{2}$ "KAZAKHSTAN RAILWAYS», JSC,

6, D. Kunayev street, Nur-Sultan, 010000, Kazakhstan

\section{${ }^{3}$ «KAZTRANSGAZ ONIMDERY», LLP, ACTING CHAIRMAN OF THE MANAGEMENT BOARD ALE "GAS MOTOR ASSOCIATION OF KAZAKHSTAN», \\ 12, A. Bokeichanstreet, Nur-Sultan, 010000, Kazakhstan}

The article substantiates the location of the main infrastructure facilities of production, refueling and outfitting points of liquefied natural gas (LNG) on the locomotive traction network of Kazakhstan railroads to provide a fleet of locomotives on gas motor fuel. Structural levels of the diesel traction railway network have been considered and regional traction zones have been determined. The methodology for determining the location of major infrastructure facilities of LNG, taking into account the size of the transported freight traffic, the length of service shoulders and zoning. In determining the locations of LNG infrastructure facilities, the location of the natural gas pipeline network in Kazakhstan is also taken into account.

KEY WORDS: LNG (liquefied natural gas), NGV fuel, gas-fueled locomotive, LNG infrastructure, locomotive outfitting points, locomotive traction network.

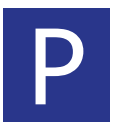

астущая тенденция по переходу на альтернативные виды топлива в транспорте диктуются не только технологическими инновациями и ограниченными ресурсами запасов нефти, но и регуляторами по защите окружающей среды и выбросам вредных веществ в атмосферу. Такие изменения коснулись не только автомобильного, но и железнодорожного транспорта.

Многие железнодорожные компании мира, также как и производители тепловозов, находятся в постоянном поиске альтернатив дизельному топливу, которое не только загрязняет воздух, но и постепенно перестает быть экономически выгодным для некоторых регионов. Среди допустимых альтернативных видов топлива для тепловозов называются сжатый природный газ, сжиженный природный газ, водородное топливо.

К примеру, в 2017 г. в Германии компания Alstom представила первый поезд на водородном топливе для пассажирского сообщения [1].

В США на железных дорогах BNSF и FED (Флорида) совместно с компаниями General Electric (GE) и Wabtec ведутся испытания и поставка тепловозов серии Evolution и Dash с двигателем на газомоторном топливе (ГМТ) технологии $\mathrm{NextFuel}^{\mathrm{TM}}$, использующем СПГ для грузовых перевозок [2]. Например, в настоящее время компания Wabtec увеличила количество эксплуатируемых тепловозов на ГМТ на железных дорогах Северной Америки и Мексики до 80 единиц.

Сегодня в парке магистральных локомотивов $A O$ «Национальная компания «Қазақстан темір жоль» (АО «НК «КТЖ») эксплуатируется 345 тепловозов серии TЭ33A (серии Evolution) с дизелем GEVO 12 компании GE. До 2025 года планируется закупить еще 101 тепловозов данной серии.

В данной статье авторы рассматривают СПГ как наиболее походящее топливо для магистрального тепловоза на сети тепловозной тяги Казахстана. Этот выбор обусловлен, в первую очередь, наличием собственных запасов газа, а также возможностью доставки дополнительных объемов СПГ из Российской Федерации, которая входит в состав основных поставщиков природного газа в мире [3]. Также учтены результаты успешного испытания Северо-Американскими железнодорожными компаниями технологии $\mathrm{NextFuel}^{\mathrm{TM}}$, которая позволяет рассматривать вариант ис- 


\section{БУДУЩЕЕ НЕФТЕГАЗОВОГО КОМПЛЕКСА}

пользования СПГ в качестве топлива для магистральных тепловозов как наиболее вероятный.

Необходимо принимать во внимание исследования по использованию СПГ в качестве замены дизельного топлива на морских судах [4], разработки по переводу дизельного двигателя на двигатель на газомоторном топливе [5], плюсы и минусы СПГ перед другими видами альтернативного топлива [6,7]. Особое место имеет оценка воздействия использования СПГ в качестве топлива на окружающую среду [8 - 10], а также стандарты РК и Агентства по защите окружающей среды (США) $[11,12]$.

В последние годы отечественные ученые в зарубежных периодических изданиях свои результаты в области применения ГМТ в качестве топлива для магистральных тепловозов $[13,14]$.

Данная статья призвана заполнить брешь между готовыми решениями по производству и доставке СПГ и разрабатываемыми новыми решениями по использованию СПГ в качестве топлива для локомотивов, предоставив методику обоснования размещения инфраструктурных объектов СПГ на примере сети тепловозной тяги $A O$ «К «КТЖ».

\section{1. Структурные уровни объектов обеспечения тепловозов СПГ}

Размещение инфраструктурных объектов на сети железных дорог $A O$ «HК «КТЖ», в том числе инфраструктурных объектов производства, обеспечения, хранения и экипировки СПГ представляют собой совокупность задач, обоснованность которых тесно связана с размером грузопотоков в регионах и на всей сети железной дороги, где перевозки осуществляются тепловозами. Также такую же важность имеет структура сети газопроводов страны.

Например, при рассмотрении вопроса размещения инфраструктурных объектов СПГ - комплекса по сжижению природного газа (КСПГ), заправочного комплекса сжиженного природного газа (ЗКСПГ), пунктов экипировки и отстоя тендеров для СПГ (ПЭТ), обеспечивающие тепловозов близлежащих основных и оборотных локомотивных депо СПГ, создается транспортный кластер уровня сквозного участка обслужсивания данных депо.

На полигонном уровне границы отдельных местных кластеров соединяются и сливаются линиями и участками железной дороги и сетями газопроводов и образуют единый транспортный кластер более высокого уровня, обеспечивающий взаимодействие различных объектов местного уровня в регионе.

Кроме того, необходимость обслуживания тупиковых железнодорожных линий и участков на сети тепловозной тяги проводит к формированию отдельного кластера - уровня тупикового обслуживания основных депо (тупикового, сквозного или частично-сквозного типа), для тягового обслуживания которых должны быть предусмотрены соответствующие условия.

Отсюда следствие - сетевой транспортный кластер обеспечения тепловозов СПГ может иметь сложную многоуровневую и иерархическую структуру, а оптимизацию обеспечения тепловозов такого уровня топливом предполагается выполнять на каждом из рассматриваемых уровней.

Это означает, что процедуре обоснования размещения объектов инфраструктуры СПГ на сети тепловозной тяги РК должен предшествовать этап определения числа уровней инфраструктуры СПГ. 


\section{БУДУЩЕЕ НЕФТЕГАЗОВОГО КОМПЛЕКСА}

В общем случае элементы инфраструктуры СПГ на сети тепловозной тяги $A O$ «HK «KTЖ» (часть сети железных дорог страны обслуживается электровозной тягой) можно разделить по иерархии на уровни с учетом той роли, которую они выполняют в процессе тягового обслуживания поездопотоков.

Это следующие уровни:

- уровень сквозного участка обслужсивания - уровень плеча обслуживания тепловозов основного депо, определяемый набором сквозных, последовательно расположенных перегонов и раздельных пунктов между двумя техническими станциями, на которых расположены основное или оборотное локомотивные депо;

- уровень полигона обслуживания - уровень обслуживания тепловозов на полигоне, определяемый как слияние нескольких сквозных железнодорожных участков (плеч обслуживания локомотивов) на железнодорожном направлении и в регионе;

- уровень тупиковых участков - определяемый в виде набора железнодорожных участков, расположенных на тупиковых линиях и участков на сети тепловозной тяги железной дороги $A O$ «HK «КTЖ».

Также необходимо учитывать, что определенные сквозные и тупиковые участки и полигоны обслуживания сети тепловозной тяги железных дорог географически распределены по регионам РК. В этой части предложенная градация уровней сети тепловозной тяги должна быть преобразована в региональные кластеры с учетом данных по участкам и полигонам.

Это приводит к следующим региональным зонам тепловозной тяги сети железных дорог РК (рисунок 1):

- зона «Север - Запад» - кластер сети тепловозной тяги, с железнодорожными участками и полигонами Западного и Северного регионов РК;

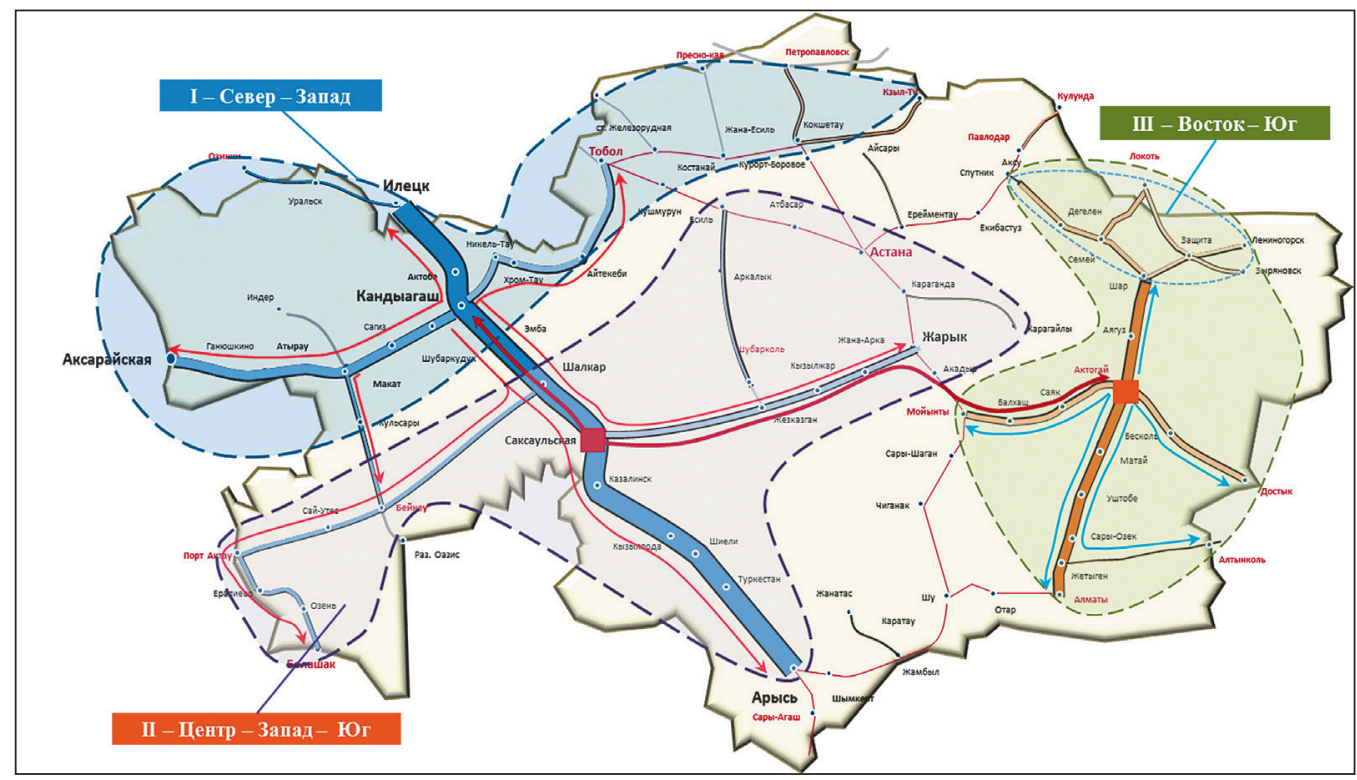

Рисунок 1 - Схематическое расположение региональных зон тяготения на сети тепловозной тяги железных дорог АО «НК «КТЖ» 
- зона «Центр - Запад - Юг» - кластер сети тепловозной тяги с железнодорожными участками и полигонами Центрального и Западного регионов (с учетом новых построенных железных дорог) и часть Южного региона РК;

- зона «Восток - Юг» - кластер сети тепловозной тяги с железнодорожными участками и полигонами всего Восточного и Южного регионов РК.

По итогам анализа в таблище 1 приведено распределение общих объемов величины грузооборота, развернутой длины и расхода дизельного топлива на зонах сети тепловозной тяги.

Таким образом, вся сеть тепловозной тяги РК разделены на 3 зоны. Очевидно, что инфраструктурные объекты СПГ (КСПГ, ЗКСПГ и ПЭТ), обеспечивающие тепловозы на газомоторном топливе близлежащих основных и оборотных локомотивных депо СПГ, должны будут размещены в границах этих зон.

2. Постановка задачи обоснования размещения инфраструктурных объектов СПГ на сети тепловозной тяги

Теперь актуальной задачей становится обоснование расположения «точек», а точнее, железнодорожных станций таких объектов.

Прежде всего отметим, что каждый из рассматриваемых структурных элементов зон тяготения (участки и полигоны) на сети тепловозной тяги характеризуется:

- принадлежностью к одной из трех обозначенных зон;

- длиной (расстоянием между точками, определяющими его положение на транспортной сети тепловозной тяги);

- величиной перевозимого грузового потока, представляющего собой общий объем грузовых перевозок $p$ за анализируемый период времени на рассматриваемой зоне в обоих направлениях.

Для тягового облуживания перевозимого объема грузовых перевозок тепловозы должны потреблять соответствующий объем топлива. Учитывая, что каждый элемент отдельной зоны на сети тепловозной тяги имеет свое значение удельного расхода топлива на $10^{4}$ т-км брутто перевозочной работы, - величина суммарного расхода топлива $G$ тепловозами на этих уровнях является различной.

С учетом указанных структурных и технологических особенностей для обозначения структурных элементов потребления газомоторного топлива (дизельного

Таблица 1 - Распределение объемов грузооборота, длины и расхода дизельного топлива по зонам сети тепловозной тяги АО «НК «КТЖ»

\begin{tabular}{|c|c|c|c|c|}
\hline \multirow{2}{*}{$\begin{array}{c}\text { No } \\
\mathbf{n} / \mathbf{n}\end{array}$} & $\begin{array}{c}\text { Наименование зон } \\
\text { грузопотоков }\end{array}$ & \multicolumn{3}{|c|}{ Доли, \% } \\
\cline { 3 - 5 } & грузооборота & $\begin{array}{c}\text { развернутой } \\
\text { длины }\end{array}$ & $\begin{array}{c}\text { расхода } \\
\text { дизельного } \\
\text { топлива }\end{array}$ \\
\hline 1 & Зона «Север-Запад» & 38,0 & 32,6 & 36,7 \\
\hline 2 & Зона «Центр - Запад - Юг» & 32,7 & 39,5 & 32,1 \\
\hline 3 & Зона «Восток- Юг» & 29,3 & 27,9 & 31,2 \\
\hline & Итого: & $\mathbf{1 0 0}$ & $\mathbf{1 0 0}$ & $\mathbf{1 0 0}$ \\
\hline
\end{tabular}


топлива и СПГ) на тепловозной сети для сквозных железнодорожных участков используются символы $a_{i}\left(i=1,2, \ldots, N_{A}\right)$, полигонов $-b_{i}\left(i=1,2, \ldots, N_{B}\right)$ и для тупиковых линий и участков $-\mathrm{c}_{i}\left(i=1,2 \ldots, N_{c}\right)$.

Совокупность всех элементов $a_{i}$ образует множество $\mathbf{A}$, характеризующее уровень сквозного участка обслуживания сети тепловозной тяги, совокупность элементов $b_{i}$ образует множество полигонов $\mathbf{B}$, и совокупность элементов $c_{i}$ образует множество тупиковых линий и участков $\mathbf{C}$.

Поскольку каждый из элементов множеств $\mathbf{A}, \mathbf{B}$, и $\mathbf{C}$ характеризуется длиной $l_{i}$ и объемом потребляемого тепловозами топлива $g_{i}$ для тягового обслуживания осваиваемого грузопотока $p_{i},-$ перечисленные характеристики можно рассматривать как координаты элементов на плоскости $g$ ol.

Тогда элементы на сети тепловозной тяги могут быть описаны набором элементов (точек на плоскости):

$$
\left\{\begin{array}{l}
a_{i}\left(l_{i}^{A}, g_{i}^{A}\right)\left(i=1,2 \ldots, N_{A}\right) \\
b_{i}\left(l_{i}^{B}, g_{i}^{B}\right)\left(i=1,2 \ldots, N_{B}\right) \\
c_{i}\left(l_{i}^{C}, g_{i}^{C}\right)\left(i=1,2 \ldots, N_{C}\right)
\end{array}\right.
$$

где $N_{A}+N_{B}+N_{C}$ - общее число структурных элементов на всей сети тепловозной тяги.

Далее можно построить некоторое поле на абсолютных значениях $\mathrm{g}_{i}$ и $l_{i}$, принадлежащих множествам $\mathbf{A}, \mathbf{B}$, и $\mathbf{C}$ в системе координат g $0 l$.

Однако в последующем такое графическое представление не позволяет четко выделять границы структурных уровней, и неприемлемо для принятия последующих решений, связанных с задачей выбора места размещения инфраструктурных объектов СПГ. Это, в первую очередь, связано с несопоставимостью значений длины $l_{i}$ и величины потребляемого топлива $g_{i}$ различных структурных элементов тепловозной сети тяги, и такая плоскость начинает «расплываться», не позволяя производить определение границ уровней.

Для решения такой задачи необходимо включить другой инструмент, а, именно методы качественной математической теории. Одним из таких приемлемых инструментов являются методы теории множеств и алгебраической (комбинаторной) топологии [15 - 17].

Другими словами, при такой постановке решение задачи сводится к созданию метода количественной оценки качественных критериев и соответствующих расчетных алгоритмов, позволяющих отказаться от визуальной оценки взаимного расположения элементов множеств $\mathbf{A}, \mathbf{B}$ и $\mathbf{C}$ на плоскости $g 0 l$. То есть, необходимо провести преобразование исходных данных, основанных на использовании величин $g$ (т/год) и $l$ (км) с указанной размерностью к безразмерным характеристикам.

Для этого координаты элементов, принадлежащих множеству А, следует преобразовать (или провести «перенормировку» координат): 


$$
\left\{\begin{array}{l}
x_{i}^{A}=\frac{l_{i}^{A}-l_{\min }}{l_{\max }-l_{\min }} \\
y_{i}^{A}=\frac{g_{i}^{A}-g_{\min }}{g_{\max }-g_{\min }}
\end{array}\right.
$$

где $l_{i}{ }^{A}$ и $g_{i}{ }^{A}-$ соответственно, длина и величина потребляемого топлива исследуемого элемента множества $\mathbf{A}, \mathbf{B}$ и $\mathbf{C}$;

$l_{\text {max }}-$ наибольшая длина транспортного элемента среди всех элементов, принадлежащих к множествам $\mathbf{A}, \mathbf{B}$ и $\mathbf{C}$;

$l_{\min }-$ наименьшая длина транспортного элемента среди всех элементов, принадлежащих к множествам $\mathbf{A}, \mathbf{B}$ и $\mathbf{C}$;

$g_{\max }$ - максимальная величина объема потребляемого топлива среди всех элементов, принадлежащих к множествам $\mathbf{A}, \mathbf{B}$ и $\mathbf{C}$;

$g_{\min }-$ минимальная величина объема потребляемого топлива среди всех элементов, принадлежащих к множествам $\mathbf{A}, \mathbf{B}$ и $\mathbf{C}$.

Аналогичным образом преобразуются координаты элементов множеств $\mathbf{B}$ и $\mathbf{C}$.

Отметим, что теперь использование процедуры замены переменных приводит к тому, что все элементы множеств $\mathbf{A}, \mathbf{B}$ и $\mathbf{C}$ будут располагаться в пределах квадрата со стороной, равной единице.

Отметим, что процедура преобразования переменных упрощает процедуру количественной оценки структурного (качественного) взаимного положения элементов множеств $\mathbf{A}, \mathbf{B}$ и $\mathbf{C}$, составляющих различные уровни на сети тепловозной тяги АО «НК «КТЖ».

Таким образом, определение границ и оценка взаимного расположения отдельных множеств, характеризующих структуру транспортной сети, служит важным этапом анализа, результаты которого определяют суть последующих действий, связанных с оптимизацией размещения объектов инфраструктуры СПГ.

\section{3. Методика оценки взаимного расположения инфраструктурных объектов СПГ на сети тепловозной тяги}

В соответствии с существующими представлениями мерой близости отдельно взятых элементов множества является расстояние между ними, которое в зависимости от характера решаемой задачи определяется различным образом [18].

Поскольку в дальнейшем возникает потребность в оценке взаимного расположения как отдельных элементов множества $\mathbf{A}, \mathbf{B}$ и $\mathbf{C}$, представляющих совокупность элементов, отражающих тот иной структурный уровень сети тепловозной тяги, то все задачи должны быть рассмотрены и решены последовательно.

Рассматривая множество элементов как совокупность конечного числа точек на плоскости $Y 0 X$, отметим, что выбор метрики или меры, позволяющей оценивать близость, становится обязательным этапом проведения структурного анализа.

Близость элементов $a_{i}\left(x_{i}^{A}, y_{i}^{A}\right)$ и $a_{j}\left(x_{j}^{A}, y_{j}^{A}\right)$, принадлежащих множеству $\mathbf{A}$, можно оценивать при помощи евклидова расстояния, определяемого на плоскости $Y 0 X$, следующим образом: 


$$
d_{i, j}^{A}=\sqrt{\left(x_{i}^{A}-x_{j}^{A}\right)^{2}+\left(y_{i}^{A}-y_{j}^{A}\right)^{2}}
$$

В этом случае понятие близости отдельных элементов совпадает с их геометрической близостью на плоскости $Y 0 X$, а характеристикой такого множества, состоящего из $N_{A}$ транспортных элементов сети тепловозной тяги, является максимальное расстояние $D_{A}$ между точками:

$$
D_{A}=\sup d(x, y) .
$$

В дальнейшем, чтобы оценить «площадь множеств» отдельных уровней сети тепловозной тяги, необходимо ввести понятие «диаметр множества», под которым понимается верхняя грань расстояний между парами точек множества. Это означает, что отдельное множество транспортных элементов $a_{i}\left(i=1,2, \ldots, N_{A}\right)$ на плоскости $Y 0 X$ может быть «покрыто» кругом с диаметром $D_{A}$.

Существует и другой подход для определения «диаметра множества» [18], когда, например, для определения центра тяжести системы точек на плоскости, в качестве центра множества выступает цеентроид, то есть точка $\bigsqcup_{A}$ на плоскости с координатами:

$$
\bar{x}_{A}=\frac{\sum_{i=1}^{N_{A}} x_{i}^{A}}{N_{A}} ; \quad \bar{y}_{A}=\frac{\sum_{i=1}^{N_{A}} y_{i}^{A}}{N_{A}} .
$$

В целом характеристики множества обладают следующими свойствами:

При большом числе элементов, присоединение к множеству нескольких точек в пределах окружности $D_{A}$ с центром в точке $\bigsqcup_{A}$ не приводит к заметному изменению положения центра - свойство устойчивости положения центроида.

Изменение диаметра множества не происходит, если значения координат каждого из его элементов увеличить (уменьшить) на одно и то же число - свойство независимости диаметра от положения начала координат.

Добавление в состав множества нового элемента приводит к увеличению его диаметра только в том случае, если при этом происходит увеличение наибольшего расстояния между элементами.

Эти перечисленные свойства множества $\mathbf{A}, \mathbf{B}$ и $\mathbf{C}$ позволяет рассматривать параметры $D_{A}, \bar{x}_{A}$ и $\bar{y}_{A}$ как важные характеристики, необходимые в дальнейшем для описания групповых свойств структурных элементов, составляющих эти множества (уровней сети тепловозной тяги).

Понятие расстояния между группами объектов (между различными структурными уровнями сети тепловозной тяги) необходимо при разработке процедуры их классификации и связано с оценкой взаимного расположения на плоскости множеств различной природы. При этом мерой близости отдельных множеств может служить расстояние, определяемое по принципу «ближнего соседа», с использованием потенциальных функций [18] и т.п. 


\section{БУДУЩЕЕ НЕФТЕГАЗОВОГО КОМПЛЕКСА}

Поскольку центр отдельного множества определяется положением центроида на плоскости $Y 0 X$, то расстояние между множествами $\mathbf{A}$ и $\mathbf{B}$, которые содержат соответственно $N_{A}$ и $N_{B}$ элементов, определяется как евклидово расстояние между центроидами $Ц_{A}$ и $Ц_{B}$ :

$$
D_{A B}=\sqrt{\left(\bar{x}_{A}-\bar{x}_{B}\right)^{2}+\left(\bar{y}_{A}-\bar{y}_{B}\right)^{2}} .
$$

Если множества $\mathbf{A}$ и $\mathbf{B}$ характеризуются значениями диаметров $D_{A}$ и $D_{B}$, то в дальнейшем такие множества оцениваются как «непересекающиеся» при выполнении неравенства:

$$
D_{A B}<\frac{D_{A}}{2}+\frac{D_{B}}{2}
$$

После преобразований это условие формулируется так:

$$
\eta_{A B}=\frac{D_{A}+D_{B}}{2 D_{A B}}-1>0 .
$$

В данном случае критерий $\eta_{A B}$ следует воспринимать как показатель парной близости множеств А и В. Он принимает положительные значения, когда множества удалены друг от друга на плоскости $Y 0 X$ и «смешивания» их элементов не происходит. В противном случае критерий $\eta_{A B}$ имеет отрицательное значение $\left(\eta_{A B} \leq 0\right)$. При этом постепенное взаимное удаление «непересекающихся» множеств А и $\mathbf{B}$ будет сопровождаться непрерывным ростом положительных значений $\eta_{A B}$.

Таким образом, с практической точки зрения, представляет интерес только положительные значения $\eta_{A B}$, поскольку именно в этом варианте анализируемая транспортная система имеет отдельные структурные уровни (в нашем случае, участка обслуживания, полигона обслуживания, сети тепловозной тяги).

Отметим, что формула (6) пригодна только для 2-х уровневых транспортных структур, поэтому необходимо развивать данную методику далее, и предложить следующий этап моделирования.

Сеть тепловозной тяги РК имеет 3-х уровневую структуру (участковый, полигонный и тупиковый), т.е. существует 3 множества $\mathbf{A}, \mathbf{B}$ и $\mathbf{C}$ с количеством транспортных элементов $N_{A}, N_{B}, N_{C}$ и диаметрами $D_{A}, D_{B}, D_{C}$, соответственно. В этом случае, по формуле (4) находятся попарные расстояния между множествами $\mathbf{A}, \mathbf{B}$ и $\mathbf{C}-D_{A B}, D_{A C}$ и $D_{B C}$.

Аналогично, по формуле (6) находятся показатели парной близости между множествами $\eta_{A B}, \eta_{A C}$ и $\eta_{B C}$. Проверяется условие их неотрицательности. Так как число транспортных уровней 3 , то теперь рассматривается единичное кубическое пространство в системе прямоугольных координат $\left(\eta_{A B}, \eta_{A C}\right.$ и $\left.\eta_{B}\right)$.

Далее рассматривается радиус-вектор $\rho$, который будет находиться внутри рассматриваемого единичного кубического пространства. 
Максимально возможной величины модуль радиус вектора $\rho$ достигает тогда, когда точка, характеризующая взаимное расположение 3-х множеств, совпадает с вершиной куба, наиболее удаленной от начала координат, т.е.:

$$
|\rho|_{\max }=\sqrt{3} \text {. }
$$

Такое положение радиус-вектора соответствует случаю наибольшего удаления всех рассматриваемых трех множеств друг от друга. И здесь для оценки взаимной близости 3-х анализируемых множеств необходимо применить показатель:

$$
\mu=\frac{1}{\sqrt{3}} \sqrt{\eta_{A B}^{2}+\eta_{A C}^{2-} \eta_{B C}^{2} \cdot}
$$

Введение нормировочного множителя $\frac{1}{\sqrt{3}}$ в формуле (7) приводит к тому, что показатель близости в трехмерном топологическом пространстве может изменяться в диапазоне значений $0 \leq \mu \leq 1$. Следовательно, можно заключить, что предложенный показатель близости в трехмерном топологическом пространстве $\mu$ нескольких «неперекрывающихся» множеств основан на учете парных показателей близости отдельных множеств и равен их среднеквадратичному значению.

Отметим, что значение $\mu=0$ отвечает случаю предельного сближения всех 3-х множеств без их взаимного перекрытия. Значению $\mu=1$ соответствует случай взаимного удаления множеств на предельно возможное расстояние. При этом по мере взаимного удаления множеств на плоскости $Y 0 X$ будет происходить и непрерывный рост соответствующего значения $\mu$.

С другой стороны, о необходимости построения поля расположения элементов различных структурных уровней сети тепловозной тяги в нормированном топологическом пространстве $Y 0 X$ было отмечено выше. Эти множества будут иметь на плоскости $Y 0 X$ центры $Ц_{A}\left(\right.$ с координатами $\bar{x}_{A}$ и $\left.\bar{y}_{A}\right), Ц_{B}\left(\right.$ с координатами $\bar{x}_{B}$ и $\left.\bar{y}_{B}\right)$ и $Ц_{C}\left(\right.$ с координатами $\bar{x}_{C}$ и $\left.\bar{y}_{C}\right)$.

Если соединить эти центры, то получится треугольник, и площадь данного треугольника $S$ тоже является такой же характеристикой взаимного расположения множеств $\mathbf{A}, \mathbf{B}$ и $\mathbf{C}$, как показатель $\mu$. Тогда увеличение площади треугольника $S$ можно интерпретировать как мерой удаления центров множеств на плоскости $Y 0 X$ : чем больше становится $S$, тем области различных множеств «разбегаются» на плоскости $Y 0 X$, т.е. становятся более «изолированными» друг от друга.

Таким образом, качественные (топологические) свойства сети тепловозной тяги железных дорог РК, как 3-х уровневой транспортной сети, в наибольшей степени будет проявляться тогда, когда ее «неперекрывающиеся» множества (структурные уровни - участковый, полигонный и тупиковый) в достаточной степени удалены друг от друга. При этом величина показателя $\mu$ стремиться к единице $(\mu \rightarrow 1)$, а величина площади треугольника $S$ стремится к максимуму ( $S \rightarrow \max$ ).

4. Оценка взаимного влияния различных уровней и выбор мест размещения инфраструктурных объектов СПГ на сети тепловозной тяги

После разработки методики количественной оценки критериев взаимного расположения различных уровней сети тепловозной тяги и создания соответствующих 


\section{БУДУЩЕЕ НЕФТЕГАЗОВОГО КОМПЛЕКСА}

расчетных алгоритмов, были произведены расчеты на основе данных работы сети тепловозной тяги железных дорог РК за 2020 г.

При расчете объемов потребления дизельного топлива и СПГ для тепловозов на газомоторном топливе также учтены следующие параметры такого перерасчета:

- коэффициент, учитывающий эффект снижения величины удельного расхода топлива при переходе на газомоторное топливо (ГМТ);

- долевое соотношение в величине удельного расхода ГМТ между дизельным топливом и СПГ.

Далее, с учетом всех перечисленных условий, производен расчет объемов расхода отдельных видов топлива - дизельного топлива и СПГ для элементов сети и каждой зоны.

Так как в статье рассматривается размещение только объектов инфраструктуры СПГ на сети тепловозной тяги железных дорог АО «НК «КТЖ», то для последующих расчетов учитываются значения величин длины отдельного элемента тепловозной сети $l_{i}$ и величины потребляемого отдельными элементами СПГ $-g_{i}^{C П Г}$.

На рисунке 2 показано расположение элементов множеств $\mathbf{A}, \mathbf{B}$ и $\mathbf{C}$ в плоскости (в системе координат $Y 0 X$ ) для преобразованной системы исходных данных для участков и полигонов всей сети тепловозной тяги. В нем показано взаимное расположение элементов всех трех множеств, состоящих из 20 элементов. Видно, что три множества А (сквозные железнодорожные участки), В (железнодорожные полигоны) и $\mathbf{C}$ (тупиковые железнодорожные участки) являются «неперекрывающимся»: их границы четко выделены в системе координат $Y 0 X$.

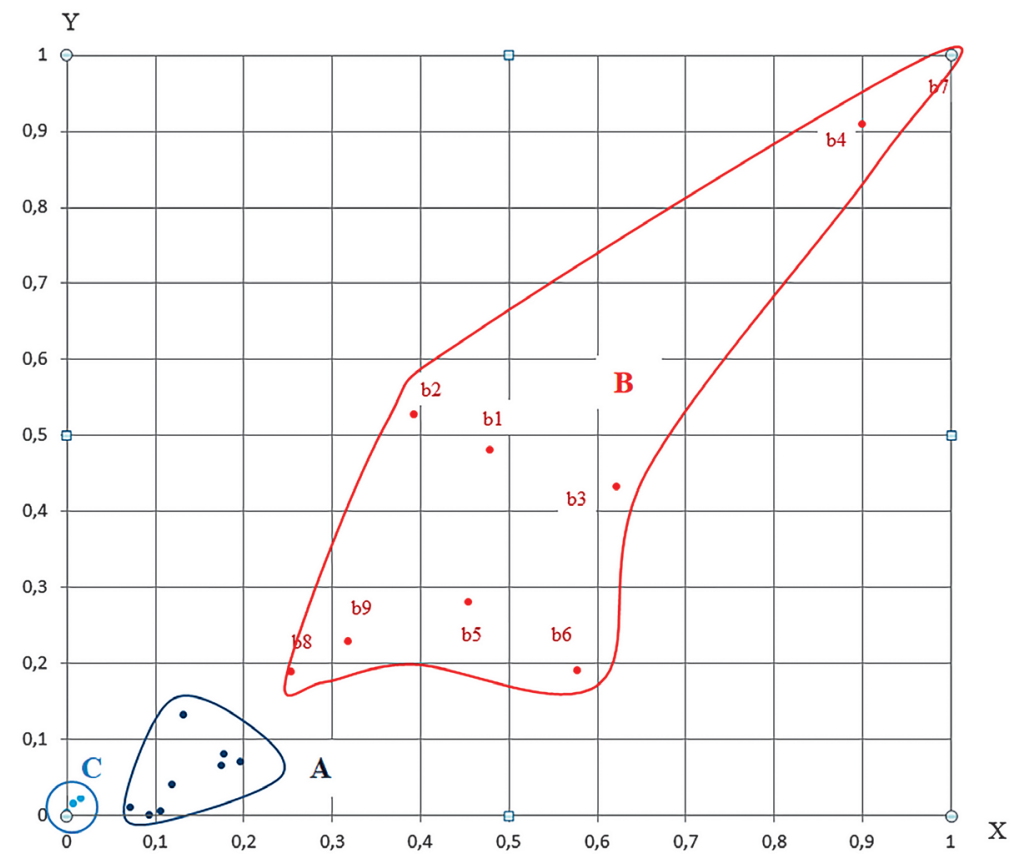

Рисунок 2 - Распределение элементов множеств А, В и С на плоскости ХOY всей сети тепловозной тяги АО «НК «КТЖ» 
В таблице 2 приведены значения показателя взаимной близости $\mu$ всей тепловозной сети и 4-х анализируемых зон по разработанной в работе методике.

\section{Таблица 2 - Значения показателя взаимной близости $\mu$ тепловозной сети и отдельных зон тяготения}

\begin{tabular}{|c|c|c|}
\hline $\begin{array}{c}\text { № } \\
\text { n/n }\end{array}$ & $\begin{array}{c}\text { Наименование зоны } \\
\text { сети железных дорог на тепловозной тяге }\end{array}$ & $\begin{array}{c}\text { Показатель парной } \\
\text { близости множеств } \mu\end{array}$ \\
\hline 1 & Сеть тепловозной тяги & 0,244 \\
\hline 2 & Зона «Север - Запад» & 0,703 \\
\hline 3 & Зона «Центр - Запад - Юг» & 0,478 \\
\hline 4 & Зона «Восток - Юг» & 0,305 \\
\hline
\end{tabular}

Анализ результатов расчета (таблица 2) показывает, что при рассмотрении всей сети тепловозной тяги, как ожидалось, все структурные уровни наиболее предельно «смешиваются» друг с другом и показатель взаимной близости $\mu$ имеет наименьшее значение $(\mu=0,244)$. Здесь, на плоскости Х0Y, имеются много «локальных» областей притяжения, состоящих из полигонов, сквозных и тупиковых линии и участков. Некоторые железнодорожные участки объединяются в крупные железнодорожные направления. Такие железнодорожные направления, как правило, входят в международные транзитные коридоры на территории РК.

Наиболее большое значение данного показателя имеет зона «Север - Запад» $(0,703)$. Это объясняется тем, что в рассматриваемой зоне основные объемы грузооборота сосредоточены в нескольких главных железнодорожных полигонах, которые имеют сетевое значение. Поэтому в данной зоне между кластерами «полигоны» и «сквозные и тупиковые участки» не существуют значительные «разрывы» на плоскости Х0Y.

Более показательна, по значению показателя $\mu$, зона «Восток - Юг» $(0,305)$. Хотя по размеру всей тепловозной сети и данной зоны несопоставимы, но структурные элементы (полигоны и участки) данной зоны также более удалены друг от друга, как у сети тепловозной тяги. Это говорит об уникальности тепловозной сети и структуры грузопотоков данной зоны. Такое обстоятельство также говорит о «изолированности» по рассмотренным характеристикам зоны «Восток - Юг» от остальных зон тяготения.

На следующем этапе, на основе анализа и оценки областей притяжения отдельных полигонов и участков сети, и различных зон притяжения на плоскости Х0Y, определены станции с наибольшего «тяготения» грузооборота, а значит и объемов расхода СПГ для тепловозов на двойном топливе (таблица 3).

Как видно из таблищь 3, на всей сети тепловозной тяги и в трех зонах имеются несколько конкурирующих станции «тяготения». Поэтому далее произведено ранжирование таких станции в порядке убывания их рейтинга в организации тепловозной тяги.

В последующем на таких станциях предполагается размещение основных инфраструктурных объектов СПГ (КСПГ, ЗКСПГ и ПЭТ) на сети тепловозной тяги железных дорог РК. 


\section{БУДУЩЕЕ НЕФТЕГАЗОВОГО КОМПЛЕКСА}

Таблица 3 - Станции «тяготения» объектов СПГ на тепловозной сети и в отдельных зонах

\begin{tabular}{|c|c|c|}
\hline $\begin{array}{c}\text { № } \\
\text { п/n }\end{array}$ & Наименование зоны & $\begin{array}{r}\text { Железнодорожные станции «тяготения» } \\
\text { объектов Спг (по иерархии) }\end{array}$ \\
\hline 1 & Сеть тепловозной тяги & Кандагач, Шалкар, Саксаульская, Актогай \\
\hline 2 & «евер - Запад» & Кандагач \\
\hline 3 & «ентр - Запад - Юг» & Саксаульская, Шалкар \\
\hline 4 & «Восток - Юг» & Актогай, Шар \\
\hline
\end{tabular}

Также особую роль при оценке и выборе места дислокации основных инфраструктурных объектов СПГ на сети тепловозной тяги играет схема существующей газопроводной сети на территории РК (рисунок 3). Учтено, что сети газопроводов на территории Республики Казахстан имеют статус различного уровня - магистрального (в т.ч. международного) и местного.

Таким образом, при выборе станции «тяготения» и места размещения основных инфраструктурных объектов СПГ принимается во внимание фактор наличия сети газопроводов вблизи данных станции, их мощность и отпускная стоимость сырья для дальнейшего сжижения топлива.

\section{ЗАКЛЮЧЕНИЕ}

Методика обоснования размещения инфраструктурных объектов СПГ для тепловозов на газомоторном топливе на примере тепловой тяги железнодорожной сети АО «НК «КТЖ» включает все необходимые параметры для эффективного размещения КСПГ, ЗКСПГ и ПЭТ.

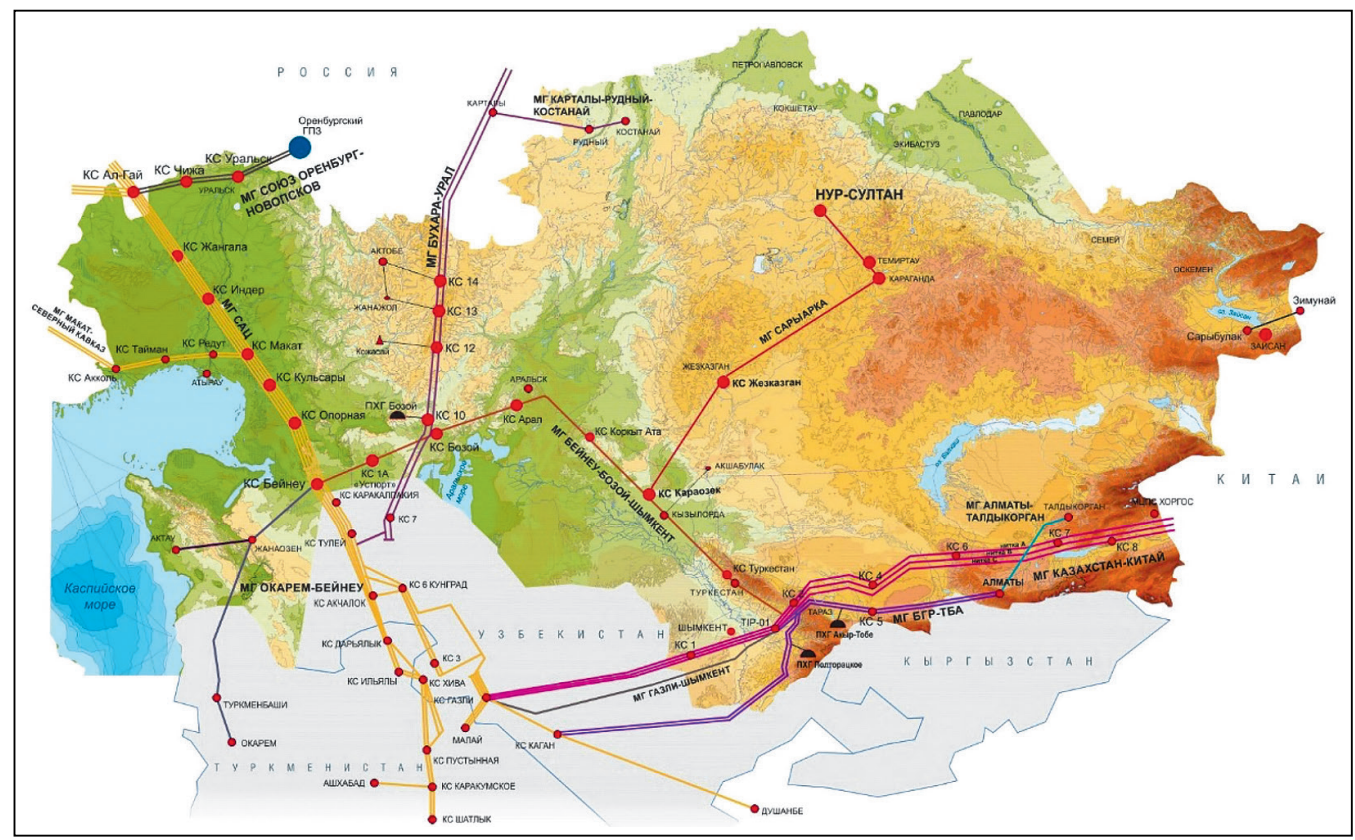

Рисунок 3 - Карта газопроводов Республики Казахстан 
При разработке методики обоснования мест размещения объектов инфраструктуры СПГ были учтены основные параметры технико-технологических процессов работы железнодорожных станций и депо в точках «тяготения».

Как видно из полученных результатов, зоны возможного использования СПГ для тепловозной тяги практически совместимы с региональными территориями Республики Казахстан, где проходят нити газопроводов природного газа.

Единственные незначительные изменения, которые могут оказать влияние на возможный перерасчет «точек» размещения инфраструктурных объектов СПГ, по мнению авторов, это технологические и технические решения производителей двигателей тепловозов на двойном топливе. При условии уменьшения или увеличения долевого соотношения в величине удельного расхода ГМТ между дизельным топливом и СПГ или технических решений по тендеру тепловоза, возникнет различие в максимальной длине пробега без дозаправки. Также незначительные изменения в расположении «точек» могут быть обусловлены изменением величины грузопотоков и, как следствие, изменения грузонапряженности внутри зон.

Авторы также допускают возможность расширения параметров, учитываемых моделью, для более точного определения «точек» размещения инфраструктуры СПГ на железнодорожном транспорте.

Таким образом, эффективное расположение объектов СПГ на сети тепловозной тяги может существенно улучшить социальный и экономический эффект для всех участников данного проекта - владельца газопровода, производителей СПГ (высокая маржинальность СПГ и доступная цена природного газа в связи с близостью газопровода), железной дороги (низкая цена на СПГ) и окружающей среды (переход на более экологически чистый и безопасный вид топлива по сравнению с дизельным топливом).

Авторы выражсают благодарность сотрудникам ТОО «Научно-исследовательский центр комплексных транспортных проблем за оказанную помощь в обработке информации и данных для статьи.

\section{ЛИТЕРАТУРА}

1 Барановская М. В Германии представили первый поезд на водородном топливе / Deutsche Welle. 09.11.2017 http://p.dw.com/p/2nNaK [Baranovskaya M. V Germanii predstavili pervyy poyezd na vodorodnom toplive / DeutscheWelle. 09.11.2017 ].

2 GE Transportation. NextFuel TM Natural Gas Retrofit https://www.getransportation.com/ locomotive-and-services/nextfuel-natural-gas-retrofit.

3 Майорец М., Симонов К. Сжиженный природный газ - будущее мировой экономики. - М.: Альпина Паблишер, 2013. - 360 c. [Mayorets M., Simonov K. Szhizhennyy prirodnyy gaz - budushcheye mirovoy ekonomiki. - M.: Al'pina Pablisher, 2013. - 360 s].

4 Ahmad Mazyar. Green ships fuelled by LNG: Stimulus for Indian coastal shipping // India Quarterly: A Journal of International Affairs. - 2014. - Vol.70. - No. 2. - Pp. 105-122.

5 Tiwari Abhay. Converting a diesel engine to dual-fuel engine using natural gas // International Journal of Energy Science and Engineering. - 2015. - Vol. 1. - No.5. - Pp. 163-169.

6 Elgohary Mohammed M, Seddiek Ibrahim S, Salem Ahmed M. Overview of alternative fuels with emphasis on the potential of liquefied natural gas as future marine fuel // 
Proceedings of the Institution of Mechanical Engineers, Part M: Journal of Engineering for the Maritime Environment. - 2015. - Vol. 229. - No.4. - Pp. 365-375.

7 Demirbas, Ayhan. Alternative fuels for transportation // Energy Exploration \& Exploitation. - 2006. - Vol. 24. - No. 1-2, - Pp. 45-54.

8 Kwon S.I, Hong J.H. Particle number and size distribution characteristics from diesel- and liquefied-natural-gas-fuelled buses for various emission certification modes in the Republic of Korea // Proceedings of the Institution of Mechanical Engineers, Part D: Journal of Automobile Engineering. - 2010. - Vol. 224. - No.12. - Pp. 1569-1579.

9 Бершадский В.Я. Экологическая безопасность железнодорожного транспорта и «зеленые» тепловозы // Транспорт Российской Федерации. - 2014. - №3 (52). - С. 27-31. [Bershadskiy V.YA. Ekologicheskaya bezopasnost' zheleznodorozhnogo transporta i «zelenyye» teplovozy // Transport Rossiyskoy Federatsii. - 2014. - №3 (52). - S. 27-31].

10 Косарев А.Б. Научное обеспечение роста энергоэффективности и экологической безопасности железнодорожного транспорта. Подходы и потенциал // Бюллетень Объединенного ученого совета ОАО «РЖД». - 2015. - № 5. - С. 1-15. [Kosarev A.В. Nauchnoye obespecheniye rosta energoeffektivnosti i ekologicheskoy bezopasnosti zheleznodorozhnogo transporta. Podkhody i potentsial // Byulleten' Ob"yedinennogo uchenogo soveta OAO «RZHD». - 2015. - № 5. - S. 1-15].

11 Государственный стандарт СТ РК ГОСТ Р 50953-2004 «Выбросы вредных веществ и дымность отработавших газов магистральных и маневровых тепловозов». Нормы и методы определения. - Астана, 2006. - 26 с. [Gosudarstvennyy standart ST RK GOST R 50953-2004 «Vybrosy vrednykh veshchestv i dymnost' otrabotavshikh gazov magistral'nykh i manevrovykh teplovozov». Normy i metody opredeleniya. - Astana, 2006. - 26 s.].

12 Environmental Protection Agency (EPA). Emission Standards for Locomotives and Locomotive Engines // Federal Register. - 1998. - Vol.63. - No.73. - Pp.18978-19084.

13 Zhardemov B. et al. Justification of location of LNG infrastructure for dual-fuel locomotives on the railway network in Kazakhstan // Procedia Computer Science. - 2019. - Vol. 149. - Рp. 548-558.

14 Канатбаев Т.А. Оценка эффрективности модернизации тепловозов ТЭЗ3А на газомоторном топливе на железных дорогах Казахстана // Техника железных дорог. - 2021. - №2 (54). - C. 18-22. [Kanatbayev T.A. Otsenka effektivnosti modernizatsii teplovozov TE33A na gazomotornom toplive na zheleznykh dorogakh Kazakhstana // Tekhnika zheleznykh dorog. - 2021. - №2 (54). - S. 18-22].

15 Александров П.С. Введение в теорию множеств и общую топологию. - М.: Наука, 1977. - 368 c. [Aleksandrov P.S. Vvedeniye $v$ teoriyu mnozhestv i obshchuyu topologiyu. - M.: Nauka, 1977, 368 s.].

16 Бурбаки Н. Общая топология. Основные структуры. - М.: Наука, 1968. - 272 с. [Burbaki N. Obshchaya topologiya. Osnovnyye struktury. - M.: Nauka, 1968. - 272 s.].

17 Свитцер Р.М. Алгебраическая топология. Гомотопии и гомологии. - М.: Наука, 1985. - 608 c. [Svittser R.M. Algebraicheskaya topologiya. Gomotopii i gomologii. - M.: Nauka, 1985. -608 s.].

18 Жардемов Б.Б. Железнодорожные транспортные комплексы: связность, неустойчивость, самоорганизация, структурные перестройки. - Астана: Astana Building, 2008. - 330 c. [Zhardemov B.B. Zheleznodorozhnyye transportnyye kompleksy: svyaznost', neustoychivost', samoorganizatsiya, strukturnyye perestroyki. - Astana:Astana Building, 2008. -330 s.]. 